\title{
Bipartite Scaphoid - First case report?
}

\author{
Dukhum Magu \\ Senior Resident, North Eastern Indira Gandhi Regional Institute of Health and Medical Sciences, Shillong, Meghalaya, India
}

Corresponding Author:

Email: drdukhum@gmail.com

\begin{abstract}
Congenital bipartite scaphoid is an extremely rare developmental anomaly of the carpal bones. There has been no previous report of bipartite scaphoid from India or any other South East Asian Countries.
\end{abstract}

\section{Introduction}

Congenital bipartite scaphoid is an extremely rare developmental anomaly of the carpal bone that have been reported in medical history..$^{1-9}$ There have also been debates about its congenital origin. But most authors believe that congenital origin is more probable than traumatic. ${ }^{3,5,6,8}$ To the best of our knowledge this rare anomaly has not been reported so far from South east Asia. This led the authors to report such a rarity.

\section{Case Report}

A 29 year old male presented to the emergency department with fracture of distal shaft of ulna. There was no pain or tenderness of the snuff box, scaphoid tubercle, on radial deviation and compression of wrist. But the wrist radiograph revealed two separate segments of scaphoid with smooth, rounded borders. At first, we presumed it to be a non-union scaphoid. The patient was put on slab for the fracture ulna and advised to follow up in OPD. Since the patient was a daily labourer we took detailed clinical history, which confirmed no past history of any significant trauma to the wrist.

Patient came to OPD after a week for cast conversion, when a repeat radiograph was taken of the fracture with the wrist (Fig. 1). And considering the smooth, rounded borders of the two scaphoid ossicles radiograph of the opposite wrist also was obtained (Fig. 2). Same findings were noted in the opposite scaphoid. The distal component was larger than the proximal one in the left side but on the right they were nearly of same size. The well-formed cortex of the ossicles showed a smooth and regular margin and the space between the ossicles was clear, as seen between the other carpals. Radiograph didn't reveal any arthritic changes in the intercarpal or wrist joint. both wrists was asymptomatic with no history of previous trauma. There were no tenderness on the anatomical snuff boxes bilaterally. The MRI of the wrists demonstrated hyaline cartilage between the the ossicles (Fig. 3 and Fig. 4).

Based on the criteria described by Jerre, Bunnel and Boys, ${ }^{2,3}$ we finally diagnosed this as a case of congenital bipartite scaphoid supported further by history, lack of symptoms corroborated by MRI findings found bilaterally. The fracture of ulna was treated conservatively with cast and it went on to heal uneventfully.

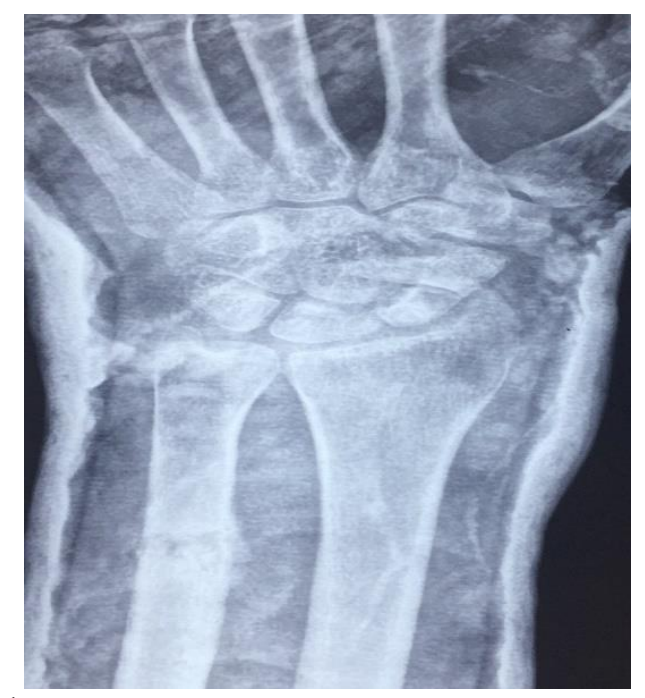

Fig. 1

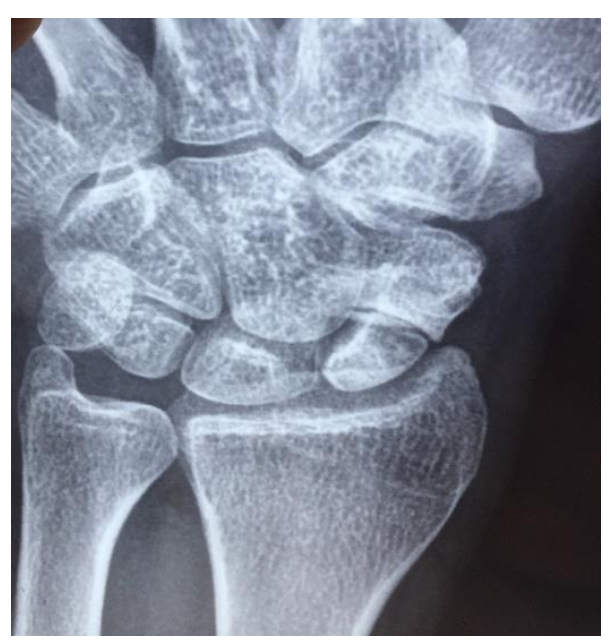

Fig. 2 


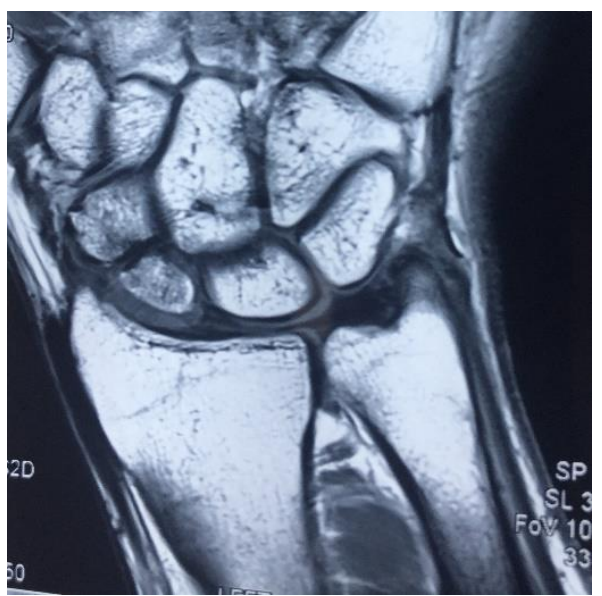

Fig. 3A

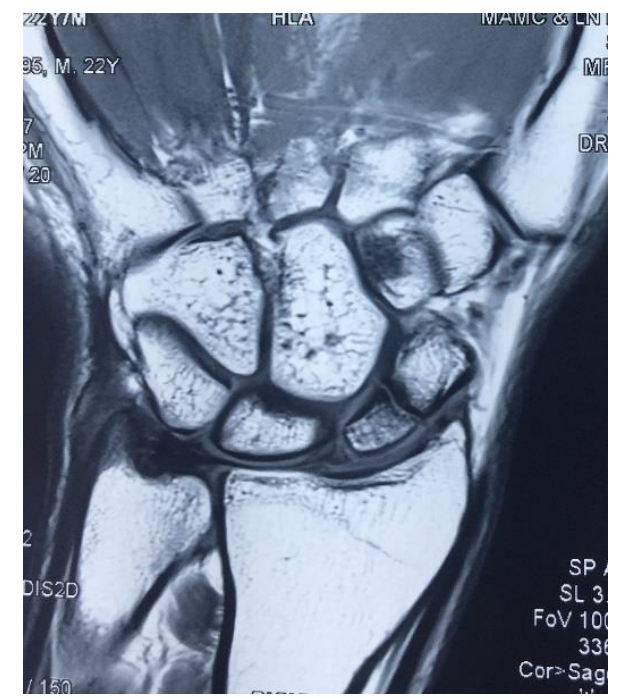

Fig. 3B

\section{Discussion}

The scaphoid usually has one ossification centre that enlarges to form a single adult scaphoid. Congenital bipartite scaphoid is a rare developmental abnormality resulting from the development of two ossification centres within the one scaphoid followed by their failure to fuse.

Bipartite carpal scaphoid was first described by Gruber $^{1}$ in 1877 . The bipartite ossicles were named Naviculare carpi secundarium radiale and ulnare. He found four examples in 3,007 dissections. Pfitzner ${ }^{8}$ in 1900, found nine cases out of 1, 456 dissections. He studied the dissected specimens in detail and advocated that bipartite scaphoid was congenital in origin, developed from two or more separate cartilage anlages. But there has been controversy of its congenital origin.

Louis et $\mathrm{al}^{4}$ in1976 studied 17439 radiographs and 196 human fetal dissections and were unable to find any proof to support its congenital origin. And they stated that bipartite scaphoid was of traumatic origin, and should be treated accordingly. Just as stated by Y Takemitsu et al, ${ }^{7}$ Louis et $\mathrm{al}^{4}$ probably didn't find bipartite scaphoid in their cases because the condition is rare. This is the first case of a bipartite scaphoid reported from the South east Asian countries till date. So, it seems that bipartite scaphoid is even more rare in this part of the world and race. Therefore, there should be research regarding racial distribution of bipartite scaphoid in future.

Wolff ${ }^{9}$ stated that a bipartite scaphoid should have hyaline cartilage in articulation between the ossicles. Hence, MRI was used by Doman and Marcus ${ }^{5}$ Chang et $\mathrm{al}^{6}$ and Whan-Yong Chung et $\mathrm{al}^{10}$ to show cartilage tissue between two ossicles while Faulkner, ${ }^{11}$ used surgical dissection.

Doman and Marcus, ${ }^{5}$ proved the congenital origin by following up an eight-year-old girl with two ossification centres of the bilateral scaphoids, until she was 17-years-old, when the the complete bipartition of the scaphoids was still persistent. Saccomann ${ }^{12}$ found two ossification centres in children with Holt-Oram Syndrome, which did not coalesce into adult age.

Jerre and Bunnel ${ }^{2,3}$ listed the criteria of bipartite scaphoid as follows:

1. Bilateral bipartition, namely, the presence of the same condition in other carpus;

2. Absence of history or signs of injury in this incidental finding;

3. Clear space between the components with smooth edges at the joint surfaces;

4. Equal size and bone density of each part and

5. Absence of degenerative changes in the radial scaphoid articulation.

So our case fulfils the above criteria for congenial bipartite scaphoid.

Patients with a congenital bipartite scaphoid usually are asymptomatic; however, once degenerative arthritis has occurred, they complain of pain and discomfort in the wrist. Whan-Yong Chung, et al ${ }^{10}$ in 2005 described cases of bipartite scaphoid with radoiocarpal osteoarthritis with symptoms similar to one that had been observed in long-standing nonunion of the scaphoid. They used bone grafting in the treatment of congenital bipartite scaphoid for patients with symptomatic scaphoid partition who present without degenerative changes with good results.

Our case was a daily wage labourer and since he didn't have any symptom of the wrists he didn't seek any intervention for it.

When dealing with non union scaphoid found incidentally it is important to do radiological evaluation of the opposite wrist especially in asymptomatic and young. So, the knowledge of bipartite scaphoid is a important to differentiate it from non union scaphoid and hence avoid unnecessary immobilisation or surgical intervention.

\section{References}

1. Gruber W, Os naviculare carpi bipartitum (5 Fall eigener Beobachtung), Virchows Archiv 69(3):391-6,1877.

2. Jerre T, Bipartite carpal scaphoid bone, Acta Orthop Scand 17:70-80,1947. 
3. Boyes JH,Bunnell's Surgery of the hand, 5th ed. Philadelphia, J.B. Lippincott:592,1970.

4. Louis DS, Calhoun TP, Garn SM, Carroll RE, Burdi HR, Congenital bipartite scaphoid-fact or fiction? J Bone Joint Surg Am 58(8):1108- 12,1976.

5. Doman AN and Marcus NW: Congenital bipartite scaphoid. J Hand Surg, 15-A:869-73,1990.

6. Chang AC, Leonello DT, Webb JM, Congenital bipartite scaphoid, J Hand Surg Euro Vol August 1, 2013.

7. Takemitsu Y1, Nakayama Y, Ota H, Matsumoto Y, Kida H,Hand Surg. 2014;19(3):427-31.

8. Pfitzner W, Beiträge zur Kenntniss des menschlichen Extremitäten- skeletes, Die morphologischen Elemente des menschlichen Handskelets, Zeitschr f Morphol 2:77$157,365-678,1900$.

9. Wolff R, Ist das Os naviculare bipartitum und tripartitum Grubers das Produkt einer Fraktur? Deutsche Zeitschr fur Chir 70:254-88,1903.

10. Sang-Bum Kim·Woo-Sik Kim·Whan-Yong Chung, et al. Bilateral Bipartite Carpal Scaphoid -A Case Report Korean Orthop Assoc 40:614-6,2005

11. Faulkner DM, Bipartite carpal scaphoid, J Bone Joint Surg 10:284-9,1928.

12. Saccomann B, Fracture of the proximal pole of the bipartite carpal scaphoid: A probable Holt-Oram syndrome, Hand (NY) 4(2):140-4, 2009. 